\title{
KESEJAHTERAAN DI SEKOLAH BAGI SISWA SMA: KONSEP DAN FAKTOR YANG BERPENGARUH
}

\author{
M. Ahkam A ${ }^{1}$, Dewi Retno Suminar ${ }^{2}$, Nurainy Fardana Nawangsari ${ }^{3}$ \\ Psikologi, Universitas Negeri Makassar ${ }^{1}$ Universitas Airlangga ${ }^{2}$ \\ Email:1‥m.ahkam.a@unm.ac.id,2 ${ }^{2}$ dewi.suminar@psikologi.unair.ac.id,

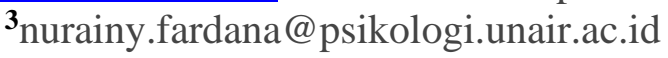

(C)2018 -JPT Fakultas Psikologi Universitas Negeri Makassar. Ini adalah artikel dengan akses terbuka di bawah licenci CC BY-NC-4.0 (https://creativecommons.org/licenses/by-nc/4.0/ ).

\begin{abstract}
ABSTRAK.
Tujuan penelitian ini adalah untuk mengetahui makna kesejahteraan di sekolah pada siswa, faktor yang berpengaruh dan dampak kesejahteraan di sekolah yang rendah. Subjek penelitian adalah siswa SMA di Surabaya sebanyak 202 siswa pada 4 (empat) sekolah. Hasil penelitian kesejahteraan di sekolah merupakan sebagai suasana yang nyaman selama siswa di sekolah yang menagcu pada aspek kepuasan di sekolah dan afek di sekolah. Kesejehteraan di sekolah dapat dipengaruhi faktor dukungan guru, dukungan teman, rasa syukur, kebersamaan, rasa syukur dan harga diri. Dampak yang dapat terjadi ketika kesejahteraan di sekolah rendah adalah psikologis siswa, perilaku negatif dan hasil akademik.
\end{abstract}

Kata kunci: kesejahteraan di sekolah, siswa

\begin{abstract}
.
The purpose of this study was to determine the meaning of school well-being on students. Influential factors and the impact of school well-being in low. The research subjects were 202 high school students in Surabaya, in 4 (four) schools. School well-being is pleasant for students in the school who are looking at aspects of satisfaction school and affect in school. School well-being influenced by teacher support, peer support, gratitude, togetherness, gratitude, and self-esteem. The impact that can occur when school well-being in low are student psychological, negative behavior, and academic results.
\end{abstract}

Keywords: school well-being, students 
PENDAHULUAN

Kesejahteraan di sekolah siswa berfokus pada kualitas kenyamanan terhadap di sekolah (Jiang, Sun, Liu, \& Pan, 2015; Sun, Jiang, Chu, \& Qian, 2014; Tian, Liu, Huang, \& Huebner, 2013). Lau \& Hue (2011) mendeskripsikan kesejahteraan di sekolah sebagai faktor penting bagi siswa yang dapat berpengaruh pada proses pembelajaran. Kesejahteraan berpengaruh positif pada siswa diantaranya siswa mampu menunjukkan perilaku positif dan sehat (Awartani, Whitman, \& Gordon, 2008).

Akan tetapi beberapa penelitian melaporkan permasalahan kesejahteraan di sekolah diantaranya Rohman dan Fauziah (2016) 5,7\% melaporkan siswa merasakan kesejahteraan yang rendah pada SMA Kesatrian 1 Semarang yang kesejahteraan di sekolah masih rendah. Selanjutnya Ahkam (2019) melaporkan siswa mengalami emosi negatif $36 \%$ dan ketidakpuasan di sekolah $36 \%$ pada siswa SMA di salah satu sekolah di Surabaya. Kesejahteraan di sekolah yang rendah dapat berdampak pada perilaku negatif diantaranya agresivitas tinggi (Nidianti \& Desiningrum, 2015), dan intensi delikuensi tinggi (Effendi \& Siswanti, 2016), yang dapat mengarah pada bullying di sekolah (Ahkam \& Fakhri, 2017).

Konsep kesejahteraan di sekolah yang digunakan pada penelitian sebelumnya memiliki konsep beragam. Konu dan Rampela (2002) menjelaskan kesejahteraan di sekolah terdiri dari 4 bagian yaitu kondisi di sekolah (having), sarana pencapaian diri di sekolah (being), hubungan sosial (loving), dan kesehatan (health). Konsep ini merupakan pengembangan konsep sosiologis kesejahteraan Allardt's dan menerapkan konsep kesejahteraan tersebut sebagai satu unit di sekolah yang membagi tiga kesejahteraan di sekolah yaitu kondisi sekolah (having), sarana pencapaian diri di sekolah (being), dan hubungan sosial (loving) (Allardt, 1973). Konsep ini dilakukan pada penelitian yang dilakukan di Beberapa penelitian di Indonesia menggunakan konsep Konu dan Rampela (2002) diantaranya penelitian Ahmad (2010), pada siswa SMA bertaraf internasional, Nidianti dan Desiningrum (2015), pada siswa SMK 4 di Kota Semarang, Ahkam dkk (2016), pada siswa SMA Negeri 1 Batang dan SMA Negeri 1 Bontoramba Kabupaten Jeneponto.

Konsep yang lain, Kesejahteraan di sekolah merupakan penilaian siswa secara subjektif dan emosional mengenai pengalaman di sekolah (Jiang et al., 2015; Sun et al., 2014; Tian et al., 2013), yang meliputi komponen kognitif dan komponen afektif (Jiang et al., 2015; Tian, Du, \& Huebner, 2014; Tian et al., 2013; Tian, Zhao, \& Huebner, 2015). Komponen 
kognitif mengacu pada kepuasan di sekolah yang digambarkan sebagai penilaian kognitif pengalaman siswa ketika berada di sekolah sedangkan komponen afektif berkaitan dengan emosi positf dan emosi negatif siswa ketika berada di sekolah. Emosi positif seperti siswa merasa rileks, senang atau bahagia sedangkan emosi negatif seperti depresi, galau, dan bosan (Tian et al., 2013), teori ini merujuk pada konsep subjective wellbeing dari Diener (1984). Lingkungan sekolah yang baik mendukung munculnya emosi positif dan membuat siswa meningkatkan kemampuan dalam pengembangan diri (Fitroh et al., 2016). Penelitian di Indonesia yang menggunakan konsep Tian dkk (2013), diantaranya adalah wijayanti dan Sulistiobudi (2018), penelitian pada siswa salah satu sekolah sekolah dasar di Bandung.

Terdapat beragam teori yang digunakan pada penelitian sebelumnya, sehingga diperlukan penelitian untuk menemukan konsep yang tepat digunakan pada konteks yang berbeda misalnya siswa SMA di Indonesia karena adanya perbedaan budaya. Tujuan penelitian ini adalah menggambarkan konsep atau persepsi siswa SMA mengenai kesejahteraan di sekolah, faktor yang dapat berpengaruh terhadap kesejahteraan di sekolah, dan dampak kesejahteraan di sekolah yang rendah.

\section{METODE PENELITIAN}

Subjek pada penelitian adalah 202 siswa pada 4 (empat) SMA di Surabaya. Metode pengumpulan data menggunakan pertanyaan terbuka dan FGD. Data yang diperoleh dari angket dan focus group discussion (fgd) dideskripsikan dalam bentuk tabel dan menggunakan pendekatan kualitatif dan teknik analisis isi sistematis dan deskriptif (Eriyanto, 2011).

\section{HASIL}

\section{A. Persepsi dan makna kesejahteraan di sekolah}

Pertanyaan terbuka diberikan kepada siswa SMA di Kota Surabaya dengan tujuan untuk mengetahui makna kesejahteraan di sekolah pada siswa. Angket terdiri dari 7 (tujuh) pertanyaan terbuka, dengan tujuan siswa dapat menceritakan dan menjelaskan secara bebas pengalaman yang dirasakan mengenai suasana yang dirasakan. Jawaban responden dirangkum dengan menggunakan pendekatan data driven dan analisis isi. Berikut rangkuman jawaban responden sebagai berikut: 
Tabel 1. Persepsi dan makna kesejahteraan di sekolah

\begin{tabular}{|c|c|c|c|}
\hline NO & Indikator & Tema & Definisi \\
\hline 1 & $\begin{array}{l}\text { a. Kegiatan proses belajar mengajar } \\
\text { berjalan dengan baik, guru } \\
\text { menerangkan dengan jelas,materi } \\
\text { pelajaran dapat dipahami dengan } \\
\text { baik, prestasi yang baik, } \\
\text { b. Hubungan interpersonal yang } \\
\text { baik seperti kebersamaan. Tidak } \\
\text { ada perbedaan ras, agama, saat } \\
\text { memiliki hubungan yang baik } \\
\text { dengan guru ataupun teman, rasa } \\
\text { kekeluargaan, tidak ada bullying, } \\
\text { hubungan yang baik dengan } \\
\text { warga sekolah } \\
\text { Fasilitas yang diperlukan untuk } \\
\text { kegiatan warga sekolah }\end{array}$ & Kepuasan di sekolah & $\begin{array}{l}\text { Siswa merasa nyaman } \\
\text { ketika berada di sekolah } \\
\text { dengan dukungan kegiatan } \\
\text { belajar mengajar berjalan } \\
\text { dengan baik,terjalin } \\
\text { hubungan interpersonal } \\
\text { yang baik, dan fasilitas } \\
\text { yang menunjang kegiatan } \\
\text { proses belajar mengajar. }\end{array}$ \\
\hline 2 & $\begin{array}{l}\text { a. Emosi positif diantaranya } \\
\text { support dari lingkungan sekolah, } \\
\text { semangat untuk belajar, rasa } \\
\text { senang dan bahagia ketika berada } \\
\text { di sekolah, senang dan nyaman } \\
\text { ketika di sekolah, tenang, } \\
\text { tenteram damai } \\
\text { b. Emosi negatif (keluh kesah, } \\
\text { cemas, stres, malas, tidak } \\
\text { nyaman, sumpek, kesal) }\end{array}$ & Afek di sekolah & $\begin{array}{l}\text { Siswa merasakan } \\
\text { lingkungan sekolah } \\
\text { memberikan efek emosi } \\
\text { positif dan emosi negatif } \\
\text { ketika berada di sekolah. }\end{array}$ \\
\hline
\end{tabular}

Hasil analisis angket pertanyaan terhadap siswa memberikan gambaran tentang makna kesejahteraan di sekolah. Jawaban subjek dirangkum ke dalam 2 tema besar yaitu 1) kepuasan di sekolah, dan 2) afek di sekolah. Tema kepuasan di sekolah dirangkum dalam 3 (tiga) indikator yaitu a) kegiatan proses belajar mengajar berlangsung dengan baik, b) hubungan interpersonal yang baik yaitu siswa dengan guru dan siswa dengan siswa yang lain, c) fasilitas yang tersedia di sekolah menunjang kegiatan. Tema afek di sekolah dengan 2 indikator yaitu emosi positf dan emosi negatif. Tahap selanjutnya membuat definisi berdasarkan tema dan indikator.

\section{B. Faktor kesejahteraan di sekolah pada} siswa

$$
\text { Pertanyaan yang kedua }
$$
menyangkut mengenai faktor-faktor yang dapat mempengaruhi atau meningkatkan kesejahteraan di sekolah. Jawaban subjek penelitian dianalisis dengan teknik analis is deskriptif . Hasil analisis dipresentasekan dan dirangkum pada tabel berikut: 
Tabel 2. Faktor yang mempengaruhi kesejahteraan di sekolah

\begin{tabular}{llll}
\hline No & $\begin{array}{l}\text { Faktor yang } \\
\text { berpengaruh }\end{array}$ & frekuensi & Presentase \\
\hline 1 & Rasa syukur & 38 & $18,8 \%$ \\
2 & Dukungan guru & 45 & $22 \%$ \\
3 & Dukungan teman & 76 & $37,6 \%$ \\
4 & Harga diri & 17 & $8,4 \%$ \\
5 & Kebersamaan & 3 & $1 \%$ \\
6 & Hubungan & 4 & $1,9 \%$ \\
7 & inrerpersonal & & $5 \%$ \\
& Lingkungan & 10 & $5,9 \%$ \\
8 & sekolah & & \\
\hline
\end{tabular}

Hasil analisis jawaban subjek penelitan mengungkapkan faktor yang dapat berpengaruh atau meningkatkan kesejahteraan di sekolah. Beberapa subjek menyebutkan lebih dari satu faktor dan $6,9 \%$ subjek yang lain tidak menyebutkan faktor yang berpengaruh.Faktor yang berpengaruh tersebut adalah rasa syukur sebesar 18,6\%, dukungan teman sebesar $37,4 \%$, dukungan guru sebesar $22 \%$, harga diri sebesar $8,4 \%$, kebersamaan, lingkungan sekolah sebesar 5\% dan hubungan interpersonal sebesar $1,7 \%$.

\section{Dampak kesejahteraan di sekolah yang rendah}

Hasil analisis menjelaskan dampak yang dirasakan atau dialami siswa ketika kesejahteraan di sekolah rendah terdiri dari 3 (tiga) tema yaitu psikologis siswa, perilaku negatif dan hasil akademik. Tema psikologis berdasarkan pada indikator malas belajar, merasa sedih, tidak senang, tidak semangat, kepercayaan rendah, stres, sumpek, kesal, merasa down, sedih, kecewa, dan bosan. Perilaku negatif berdasarkan indikator terbentuknya kelompok tertentu seperti ras, kelompok kaya, sulit beradaptasi, merasa terkecilkan. Hasil akademik berdasarkan indikator ingin bolos, kurang minat mencari ilmu, kurang minat ke sekolah. Dampak tersebut dapat dilihat dalam tabel berikut:

Tabel 3. Dampak kesejahteraan di sekolah yang rendah

\begin{tabular}{|c|c|c|}
\hline No & Indikator & Tema \\
\hline 1 & $\begin{array}{ll}\text { a. } & \text { Malas belajar } \\
\text { b. } & \text { Merasa sedih,tidak } \\
& \text { tenang, } \\
& \text { semangat, } \\
\text { c. } & \text { Kepercayaan yang } \\
& \text { rendah } \\
\text { d. Stres } \\
\text { e. Merasa sumpek dan } \\
\text { kesal } \\
\text { f. } \\
\text { Merasa down, sedih, } \\
\text { gecewa } \\
\text { Bosan }\end{array}$ & $\begin{array}{l}\text { Psikologis } \\
\text { siswa }\end{array}$ \\
\hline 2 & $\begin{array}{l}\text { a. Terbentuk } \\
\text { kelompok tertentu } \\
\text { b. Sulit beradaptasi } \\
\text { dengan yang lain } \\
\text { c. Merasa terkecilkan }\end{array}$ & $\begin{array}{l}\text { Perilaku } \\
\text { negatif }\end{array}$ \\
\hline 3 & $\begin{array}{ll}\text { a. Ingin bolos } \\
\text { b. Kurang minat } \\
\text { mencari ilmu, } \\
\text { c. Kurang minat ke } \\
\text { sekolah }\end{array}$ & $\begin{array}{l}\text { Hasil } \\
\text { Akademik }\end{array}$ \\
\hline
\end{tabular}

\section{PEMBAHASAN}

Hasil penelitian menjelaskan kesejahteraan di sekolah pada siswa SMA memaknai sebagai suasana yang nyaman ketika berada di sekolah dengan aspek kepuasan di sekolah dan afek di 
sekolah. Makna tersebut sesuai dengan konsep dari Tian dkk (2013), menjelaskan kesejahteraan di sekolah adalah siswa mengevaluasi secara subjektif dan emosional terhadap kehidupan mereka di sekolah yang berfokus pada kualitas kenyamanan di sekolah. (Jiang et al., 2015; Sun et al., 2014; Tian et al., 2013). Evaluasi yang dilakukan meliputi komponen kognitif yang menekankan penilaian secara khusus kualitas kepuasan di sekolah. Kualitas kehidupan di sekolah diantaranya siswa dapat menunjukkan prestasi yang di di sekolah, sekolah memiliki peraturan sekolah dan fasilitas yang baik, siswa memiliki hubungan yang baik dengan guru dan siswa yang lain, kualitas metode pengajaran para guru di sekolah, kurikulum serta tugas yang diberikan adalah wajar (Tian, Wang, \& Scott, 2014). Komponen afektif yaitu afek positif di sekolah seperti seberapa sering emosi positif seperti gembira dan afek negatif di sekolah seperti seperti sering emosi seperti kecemasan. Konsep ini merujuk pada teori Diener (1984), berdasarkan konsep kesejahteraan subjektif, hanya pada konteks lingkungan sekolah.

Hasil analisis menjelaskan bahwa faktor yang berpengaruh terhadap kesejahteraan di sekolah adalah dukungan teman, dukungan guru, rasa syukur, harga diri, hubungan interpersonal, lingkungan sekolah, kebersamaan. Beberapa penelitian sebelumnya melaporkan kesejahteraan di sekolah dapat dipengaruhi dukungan yang berkaitan dengan sekolah yaitu dukungan teman dan dukungan guru (Tian et al., 2013, 2015), harga diri (Tian et al., 2013), hubungan interpersonal (Sun et al., 2014), rasa syukur (Jiang et al., 2015; Sun et al., 2014).

Hasil analisis juga menjelaskan kesejahteraan di sekolah yang rendah dapat berdampak pada psikologi siswa, perilaku negatif siswa dan berkaitan dengan akademik. Beberapa penelitian sebelumnya menjelaskan kesejahteraan di sekolah yang rendah dapat berdampak pada psikologis siswa diantaranya Pada psikologis siswa yaitu prokrastinasi tinggi (Annisa \& Kristina, 2014), konsentrasi tidak fokus belajar (Khatimah, 2015; Scrimin et al., 2016), Dampak pada perilaku negatif siswa seperti merokok, menggunakan narkoba, minuman alkohol dan suntikan obat terlarang (Zullig et al., 2001), agresivitas tinggi (Nidianti \& Desiningrum, 2015). Dampak pada hasil akademik diantaranya nilai perilaku siswa di kelas dan putus sekolah Huebner dkk (2009,Tian, dkk,2013).

\section{SIMPULAN}

Simpulan hasil penelitian ini sebagai berikut: 
1. Kesejahteraan di sekolah adalah siswa merasa nyaman ketika berada di sekolah yang yang melibatkan aspek kepuasan di sekolah dan afek di sekolah. Indikator kepuasan di sekolah terdiri dari Kepuasan di sekoah berdasarkan indikator, kegiatan proses belajar mengajar berjalan dengan baik, hubungan interpersonal dan, fasilitas yang diperlukan untuk kegiatan. Indikator afek di sekolah terdiri dari emosi positid dan emosi negatif yang dialami dan dirasakan siswa di sekolah

2. Terdapat beberapa faktor yang mempengarhu kesejahteraan di sekolah yaitu dukungan yang berkaitan dengan sekolah yakni dukungan teman, duikungan guru, dan dukungan yang lingkungan sekitar.Faktor yang lain adalah rasa syukur, harga diri, hubungan interpersonal dan kebersamaan.

3. Beberapa dampak yang dirasakan dan dialami siswa apabila kesejahteraan di sekolah rendah yaitu dampak pada psikologio siswa misalnya kurang semangat mengikuti pelajaran, dampak perilaku negatif dan hasil akademik.

Implikasi penelitian adalah :
1. Siswa dapat meningkatkan kesejahteraan di sekolah dengan cara berusaha mendukung siswa yang lain untuk selalu bersemangat mengikuti kegiatan belajar mengajar dan menjalin hubungan interpersonal yang baik dengan guru dan siswa yang lain

2. Pihak sekolah dapat menfasilitasi siswa untuk dapat meningkatkan rasa syukur dan harga diri. Kegiatan tersebut dapat dilakukan pada saat proses belajar berlangsung di kelas dan kegiatan sekolah yang lain misalnya pada saat penerimaan siswa baru, kegiatan osis dan kegiatan ekstra kokurikuler yang lain.

3. Penelitian selanjutnya perlu dilakukan uji model untuk mengetahui posisi faktor atau variabel dalam model dan seberapa besar kontribusi faktor atau variabel tersebut. Dan juga dapat dijadikan sebagai dasar dalam pembutan modul untuk intervensi di sekolah.

\section{DAFTAR PUSTAKA}

Ahkam, M. A. (2019). Gambaran Kesejahteraan di sekolah pada siswa SMA. School Well-Being Di Era Revolusi Industri 4.0, 6-7. Surabaya: Fakultas Psikologi Universitas Hangtuah Surabaya.

Ahkam, M.A., \& Fakhri, N. (2017). 
Bullying pada siswa SMA. Jurnal Psikologi TALENTA, 2 (2).

Ahkam, M. A., Arifin, N. A. I., \& Kurniawan, W. (2016). Gambaran school Well-being pada remaja di Jeneponto. Strengthening Humanity by Promoting Wellness, 181-186. Surabaya: Fakultas Psikologi Universitas Katolik Widya Mandala Surabaya.

Ahmad, J. N. (2010). Penggunaan school well-being pada Sekolah Menengah atas ( SMA ) bertaraf internasional sebagai barometer evaluasi sekolah. $1,100-112$.

Allardt, E. (1973). A welfare model for selecting indicators of national development. Policy Sciences, 4(1), 63-74. Retrieved from http://link.springer.com/article/10.100 7/BF01404933

Awartani, M., Whitman, C. V., \& Gordon, J. (2008). Developing instruments to capture young people' s perceptions of how school as a learning environment affects their well-being. European Journal of Education, 43 Nomor 1(1).

Diener, E. (1984). Subjective Well-Being. American Psychological Association, Inc, 95(3), 542-575.

Effendi, A. S., \& Siswanti. (2016). Hubungan antara school well-being dengan intensi delinkuensi pada siswa kelas XI SMK Negeri 5 Semarang. Jurnal Empati, 5(April), 195-199.

Eriyanto. (2011). Analisis isi. Jakarta: PrenadaMeddia group.

Fitroh, N. (2016). Mengapa remaja Bugis Makassar bersyukur?: Pendekatan indigenous psychology. INQUIRY: Jurnal Ilmiah Psikologi, 7(2).

Jiang, H., Sun, P., Liu, Y., \& Pan, M. (2015). Gratitude and Late Adolescents' School Well-being: The Mediating Role of Materialism. Social Indicators Research, 127(3), 1363-1376. https://doi.org/10.1007/s11205-0151007-5
Konu, A., \& Rimpelä, M. (2002). Wellbeing in schools : a conceptual model. Health Promotion International, 17(1), 79-87.

Lau, N., \& Hue, M. (2011). Preliminary outcomes of a mindfulness-based programme for Hong Kong adolescents in schools: well-being, stress and depressive symptoms. International Journal of Children's Spirituality, 16(4), 315-330. https://doi.org/10.1080/1364436X.20 11.639747

Nidianti, W. E., \& Desiningrum, D. R. (2015). Hubungan antara school wellbeing dengan agresivitas. Jurnal Empati, 4(1), 202-207.

Rohman, I. H., \& Fauziah, N. (2016). Hubungan antara adversty intelegence dengan school well-being ( Studi pada Siswa SMA Kesatrian 1 Semarang ). 5(April), 322-326.

Sun, P., Jiang, H., Chu, M., \& Qian, F. (2014). Gratitude and school wellbeing among chinese university students: interpersonal relationships and social support as mediators. Social Behavior and Personality: An International Journal, 42(10), 16891698.

https://doi.org/10.2224/sbp.2014.42.1 0.1689

Tian, L., Du, M., \& Huebner, E. S. (2014). The Effect of Gratitude on Elementary School Students, Subjective Well-Being in Schools: The Mediating Role of Prosocial Behavior. https://doi.org/10.1007/s11205-0140712-9

Tian, L., Liu, B., Huang, S., \& Huebner, E. S. (2013). Perceived social support and school well-being among Chinese early and middle adolescents: The mediational role of self-esteem. Social Indicators Research, 113(3), 991-1008. https://doi.org/10.1007/s11205-0120123-8

Tian, L., Wang, D., \& Scott, E. (2014). 
Development and validation of the brief adolescents? subjective wellbeing in school scale (BASWBSS). Social Indicators Research, 120(December 2014), 615-634. https://doi.org/10.1007/s11205-0140603-0

Tian, L., Zhao, J., \& Huebner, E. S. (2015). School-related social support and subjective well-being in school among adolescents: The role of self- system factors. Journal of Adolescence, 45, 138-148. https://doi.org/10.1016/j.adolescence. 2015.09.003

Wijayanti, P. A. K., \& Sulistiobudi, R. A. (2018). Peer Relation Sebagai Prediktor Utama School Well-Being Siswa Sekolah Dasar. Jurnal Psikologi, $\quad 17(1), \quad 56$. https://doi.org/10.14710/jp.17.1.56-67 